\title{
Comparative Study of the Efficacy of Potassium Chloride and Sodium Bicarbonate As An Adjuvant to Bupivacaine in Supraclavicular Subclavian Perivascular Approach of Brachial Plexus Block
}

\author{
Dr.Shobana, Dr.VairavarajanChandrasekaran \\ Institute of Anaesthesiology, Madurai Medical College, Madurai
}

\begin{abstract}
Brachial plexus block is performed as a supplementation to general anaesthesia to reduce the analgesic requirements, better tourniquet tolerance as well as to provide post-operative analgesia. Adjuvants are added to improve the quality of anaesthesia and also to improve the duration of post-operative analgesia.In this study $30 \mathrm{ml}$ of $0.375 \%$ of Bupivacaine with $0.2 \mathrm{mmol}(0.1 \mathrm{ml})$ of potassium chloride of $15 \%$ solution which contains $20 \mathrm{mmol} / 10 \mathrm{ml}$ is compared with $30 \mathrm{ml}$ of $0.375 \%$ of Bupivacaine with $0.179 \mathrm{mmol}(0.2 \mathrm{ml})$ of $7.5 \%$ of sodium bicarbonate which contains $0.893 \mathrm{mmol/litre}$ regarding the quality and quantity of blockade in brachial plexus block for upper limb surgeries. This study showed that in brachial plexus blockade, the addition of potassium chloride as an adjuvant to bupivacaine shortens the onset time of sensory and motor blockade whereas the addition of sodium bicarbonate prolongs the duration of sensory and motor blockade. The quality of anaesthesia is good in both the groups.
\end{abstract}

Keywords: Bupivacaine, adjuvants, brachial plexus block

\section{Introduction}

Pain is an unpleasant sensory and emotional experience that occurs in response to tissue damage. Every patient has the right to get rid of pain and it is the duty of every anaesthetist to provide adequate pain relief.Pain relief is provided by various methods like oral drugs, nerve blocks but adequate pain relief is provided by interrupting the transmission of pain. Peripheral nerve blocks provide longer and more localized pain relief than systemic opioids and non-steroidal anti-inflammatory drugs.

Brachial plexus block is performed as a supplementation to general anaesthesia to reduce the analgesic requirements, better tourniquet tolerance as well as to provide post-operative analgesia. Brachial plexus is used as a sole anaesthetic technique in situation where general anaesthesia is relatively contraindicated e.g. emergency situation where the starvation time is inadequate, and if proper precautions are not taken, may lead to aspiration of stomach contents.

Successful brachial plexus block for upper limb surgeries requireswide knowledge about the anatomy of its origin and its branches,complications that would occur in various approaches as well as the clinical application of local anaesthetics and various adjuvants added to it inorder to provide better quality of blockade as well as prolong the duration of post-operative analgesia. At the same time the motor blockade should not be prolonged for a long time that prolongs the hospital stay.Brachial plexus can be easily blocked because they lie in a sheath and by eliciting paresthesia of one of the roots/trunk/cords can give a success rate by injecting large volume of local anaesthetic solution. In order to provide better anaesthesia in the intraoperative period as well as to provide better analgesia in the post-operative period, various adjuvants are added to local anaesthetic solution like Sodium bicarbonate, Potassium chloride, Adrenaline, Dexmedetomidine, Clonidine, Midazolam, Fentanyl, Tramadol, Dexamethasone, etc.

In most of the peripheral nerve blocks lignocaine and bupivacaine are mixed together and used. Lignocaine provides early onset of blockade whereas bupivacaine prolongs the duration of blockade.If an inadvertent accidental injection of these two drugs occurs they produce serious complications involving cardiovascular and central nervous system. Hence in this study only bupivacaine is used so that side effect of atleast one drug is avoided if a situation arises to face the detrimental effects of local anaesthetic toxicity if accidentally injected intravascularly.

Adjuvants are added to improve the quality of anaesthesia and also to improve the duration of postoperative analgesia. Classically Adrenaline is added which prevents the systemic absorption of the local anaesthetics and thus prolongs the duration of analgesia. But it has got detrimental effect of increasing the heart rate, blood pressure, and thereby it can cause coronary vasoconstriction. The other adjuvants can cause side effects like vomiting, pruritis, altered hemodynamic stability, sedation etc.

In this study $30 \mathrm{ml}$ of $0.375 \%$ of Bupivacaine with $0.2 \mathrm{mmol}(0.1 \mathrm{ml})$ of potassium chloride of $15 \%$ solution which contains $20 \mathrm{mmol} / 10 \mathrm{ml}$ is compared with $30 \mathrm{ml}$ of $0.375 \%$ of Bupivacaine with $0.179 \mathrm{mmol}(0.2 \mathrm{ml})$ of 
$7.5 \%$ of sodium bicarbonate which contains $0.893 \mathrm{mmol} /$ litre regarding the quality and quantity of blockade in brachial plexus block for upper limb surgeries.

\section{Aim}

To compare the efficacy of potassium chloride and sodium bicarbonate as an adjuvant to bupivacaine in supraclavicular subclavian perivascular approach of brachial plexus block.

\section{Materials And Methods}

This is a prospective randomized single blinded study conducted at Government Rajaji Hospital, attached to Madurai Medical College, Madurai. Sixty patients of ASA grade I\&II of either sex aged above $18 \mathrm{yrs}$, weighing over $40 \mathrm{~kg}$, undergoing upper limb surgeries and who gave written informed consent were randomly allocated into two groups; the Group BK and Group BS. The patients who were unwilling to give consent, those with infection at the puncture site, with documented neuromuscular disorders, hyperkalemia, with respiratory compromise, with known allergy to local anaesthetic drug, ASA grade III and IV patients, with psychiatric illness, BMI > 35, pregnant, with bleeding diathesis, on Anti-coagulants, with peripheral Neuropathy were excluded. During the preoperative period blood investigation including Hemoglobin, Random blood sugar, Serum Electrolytes, Urine- albumin and sugar, Chest x-ray, Electrocardiogram were done.

Each group comprises of 30 patients. The drug received by the two group are:

- GROUP BK: $0.375 \%$ of Inj.Bupivacaine + Inj.Potassiumchloride $0.2 \mathrm{mmol}(4$ units in a Insulin syringe $=0.1 \mathrm{ml}$ )

- GROUP BS: $0.375 \%$ of Inj.Bupivacaine +Inj.Sodiumbicarbonate $0.17 \mathrm{mmol}(8$ units in a insulin syringe $=0.2 \mathrm{ml})$

\section{Technique:}

The patients are explained about the procedure in their own mother tongue regarding the paraesthesia that will be elicited during the technique which is perceived as a "electric shock" like or "tingling" sensation in the elbow or in the fore-arm. Once the patient experiences the sensation he or she has to communicate with the performer. Then an intravenous access is secured and all the necessary monitors were connected. All Patients were premedicated with aInj.Midazolam $0.1 \mathrm{mg} / \mathrm{kg}$ intramuscular to reduce anxiety one hour before surgery.

The patient is positioned in supine, with the head turned $30^{\circ}$ to the contralateral side and the arms are held in adduction position close to his or her body.A shoulder roll is kept in such a way to produce an head down of $30^{\circ}$.The area of neck is aseptically painted and draped. The posterior border of the sternocleidomastoid muscle is traced from the mastoid process to the insertion at the sternal and clavicular joint.The posterior edge of the sternocleidomastoid muscle is easily palpated by asking the patient to lift the head which makes it prominent. The subclavian artery is palpated from the lateral edge of the clavicular head of sternoclavicular joint at the level of sixth cervical vertebra. An intradermal wheal is raised approximately $1 \mathrm{~cm}$ above the midclavicular point. A 22 gauge intramuscular needle which is connected to the extensiontube with a $10 \mathrm{ml}$ syringe and a second anaesthetist is ready with loaded local anaesthetic solution to inject the drug. The needle is inserted posterior, downwards and in a medial direction and slowly walked in for eliciting paraesthesia. Once paraesthesia is elicited, $30 \mathrm{ml}$ of $0.375 \%$ of inj. Bupivacaine with Inj. potassium chloride $0.2 \mathrm{mmol}$ in Group BK or $0.375 \%$ of inj. Bupivacaine with inj. sodium bicarbonate $0.17 \mathrm{mmol}$ in Group BS is injected by the second anaesthetist after confirming negative aspiration.

The time of onset of sensory block, is recorded using pinprick in fourth cervical to first thoracic dermatome once in every one minute till the blockade occurs. There after every one hour till patient regained normal sensations. The onset of sensory block is the time of injection of drug to time of loss of pain on pinprick. The sensory blockade is assessed and scored as follows.

- $\quad$-No pain

- 1-Mild grimace

- 2-Moderate pain-Withdrawal

- 3-Severe pain-Screams

The time of onset of motor blockade is recorded by modified Bromage score. It is assessed every one minute till the motor blockade occurs. Thereafter every one hour it is assessed till recovery of motor power (flexion of elbow).

0: Able to raise extended arm to $90^{\circ}$ for 2 secs

1: Able to flex elbow and move fingers but unable to raise the extended arm

2: Unable to flex the elbow but able to move the fingers

3: Unable to move arm, elbow, and fingers. 
The duration of surgery, the duration of sensory block, the duration of motor block, the vital parameters and complications were recorded. The duration of sensory blockade was the time of onset of sensory block to the recurrence of pain to pinprick. The duration of motor blockade was the time of onset of loss of movements to the recurrence of movements. The heart rate,blood pressure, arterial saturation were recorded every 5 minutes intraoperatively. The patients were monitored for bradycardia, hypotension, convulsions, restlessness, disorientation, drowsiness or any other complications. The quality of sensory and motor blockade was assessed based on the sensory and motor blockade as

Grade 1: No supplemental drugs like opioids or sedatives are required in the intra operative period to continue the surgery Grade 2: Analgesics and sedatives are given as supplementation due to inadequate blockade.Grade 3: Due to complete failure of the blockade and hence converted to general anaesthesiaand these patients are excluded from the study. The change in $\mathrm{pH}$ observed in this studyfor $0.5 \% 20 \mathrm{ml}$ of Bupivacaine, $0.375 \%$ of $30 \mathrm{ml}$ Bupivacaine, $0.375 \%$ of Bupivacaine with $0.1 \mathrm{ml}$ of potassium chloride is $\mathrm{pH} 5$ and for $0.375 \%$ of Bupivacaine with $0.2 \mathrm{ml}$ of sodium bicarbonate is $\mathrm{pH} 7$

\section{Data Analysis}

The information collected regarding all the selected cases were recorded in a Master Chart. Data analysis was done with the help of computer using Epidemiological Information Package (EPI 2010)developed by Centre for Disease Control, Atlanta.Using this software range, frequencies, percentages, means, standard deviations, chi square and $\mathrm{P}$ values were calculated. Kruskul Wallis chi-square test was used to test the significance of difference between quantitative variables and Yate's chi square test for qualitative variables. A ' $\mathrm{p}$ ' value less than 0.05 is taken to denote significant relationship.

\section{Results}

Sixty patients of ASA grade I\&II of undergoing upper limb surgeries were randomly allocated into two Groups BK and BS. Each group comprised of 30 patients. Most of them were males and were in ASA Grade I. Table 1 shows the study parameters findings. The tourniquet tolerance was good and Quality of anaesthesia was of grade I in both groups. In Group BK and in Group BS there were no ECG changes. In Group BK and Group BS complications like nausea, vomiting. Hypotension, hypertension Tachycardia. Bradycardia were absent.

\section{Discussion}

Brachial plexus block is widely used in our day to day practice for elective as well as emergency upper limb surgeries. It provides better intra-operative as well as post-operative analgesia. Inorder to provide better quality of anaesthesia intraoperatively as well as to prolong the duration of post-operative analgesia various adjuvants are added to local anaesthetic solution. Among the adjuvants sodiumbicarbonate and potassium chloride have stood the test of time, apart from the opioids.

The addition of sodium bicarbonate to Bupivacaine alkalinizes the $\mathrm{pH}$ of the local anaesthetic solution thereby free base is liberated, ion trapping occurs and hence the onset of sensory block is enhanced rapidly. The addition of potassium chloride to Bupivacaine increases the extracellular concentration and depolarizes the nerve membrane and thus blocks the conduction of nerve impulses. The addition of potassium chloride to bupivacaine shortens the onset of sensory and motor blockade whereas the addition of sodium bicarbonate to bupivacaine prolongs the duration of sensory and motor blockade in brachial plexus block.

The addition of potassium chloride as an adjuvant to Bupivacainesolution will cause depolarization of the cell membrane and thereby it provides better quality of analgesia, better tourniquet tolerance as well as prolongs the duration of analgesia. It also enhances the onset of sensory blockade which would be prolonged with plain bupivacaine alone without any detrimental side effect even when injected intravascularly because $0.2 \mathrm{mmoles}$ of potassium chloride used in this study is too low to cause the cardiovascular complications.

Sodium bicarbonate when added as an adjuvant to Bupivacaine will change the $\mathrm{pH}$ to alkaline state and thereby it enhances the onset of sensory blockade as well as provides better quality of analgesia, better tourniquet tolerance and prolongs the duration of analgesia.The addition of potassium chloride and alkalinization of the local anaesthetic solution is used which is cost effective as well as do not have any adverse effect on the hemodynamic status of the individual. The addition of carbonates and alkalinization have stood the test of time.

This study was carried out in sixty patients of ASA I and II with demographic data in terms of age, weight, sex, body mass index were similar in both the groups. The result of this study supports the findings of Khosa et al who showed that addition of potassium chloride to bupivacaine significantly enhanced the onset of both sensory and motor blockade. In contrast to this study the delayed onset of blockade proposed by Parris and Chamber et al may be due to the lower concentration of Bupivacaine $(0.25 \%)$ when compared to this study $(0.375 \%)$. 
The quality of sensory and motor block was same in both the groups. The patients did not require supplemental analgesics or sedatives in both the group. Bromage and Burfoot also found the intense quality of blockade when potassium was added to lignocaine in epidural blockade. This also correlates with the results of Parris and Chamber et al.The duration of sensory and motor blockade was significantly increased in both the groups more so in BS group.This observation correlates with Khosa et al who found prolonged duration of analgesia.

Hence it is concluded that, in brachial plexus blockade, the addition of potassium chloride as an adjuvant to bupivacaine shortens the onset time of sensory and motor blockade whereas the addition of sodiumbicarbonate prolongs the duration of sensory and motor blockade. The quality of anaesthesia is good in both the groups.

Table: 1 Comparison between BK and BS groups

\begin{tabular}{|l|l|l|l|l|l|l|}
\hline S.No & \multirow{2}{*}{ Study Parameters } & Group BK & \multicolumn{2}{l|}{ Group BS } & P value \\
\cline { 3 - 6 } & & Mean & SD & Mean & SD & \\
\hline 1 & Age (in yrs) & 40.7 & 14.3 & 37.9 & 14.5 & 0.4717 \\
\hline 2 & BMI & 23.2 & 1.8 & 23.8 & 4.6 & 0.2675 \\
\hline 3 & Time of onset of sensory bloc (in mins) & 7.63 & 0.56 & 9.83 & 0.64 & $\mathbf{0 . 0 0 0 1}$ \\
\hline 4 & Time of motor onset (in mins) & 3.9 & 0.31 & 5.2 & 0.41 & $\mathbf{0 . 0 0 0 1}$ \\
\hline 5 & Duration of Surgery (in mins) & 88 & 14.1 & 83 & 18.1 & 0.0147 \\
\hline 6 & Systolic Blood Pressure (mmHg) & 117 & 13.2 & 119 & 13.7 & 0.555 \\
\hline 7 & Diastolic Blood Pressure (mmHg) & 70.7 & 8.3 & 70.3 & 8.1 & 0.9425 \\
\hline 8 & Pulse Rate (per min) & 75.9 & 7.3 & 76 & 9.3 & 0.8236 \\
\hline 9 & SPO (\%) & 98.5 & 0.7 & 98.5 & 0.7 & 1.0 \\
\hline 10 & Sensory Block Duration (in mins) & 476.6 & 13.2 & 608 & 26.1 & $\mathbf{0 . 0 0 0 1}$ \\
\hline 11 & Duration of Motor Block (in mins) & 245 & 11.4 & 417 & 12.1 & $\mathbf{0 . 0 0 0 1}$ \\
\hline
\end{tabular}

\section{Conclusion}

In brachial plexus blockade, the addition of potassium chloride as an adjuvant to bupivacaine shortens the onset time of sensory and motor blockade whereas the addition of sodium bicarbonate prolongs the duration of sensory and motor blockade. The quality of anaesthesia is good in both the groups.

\section{References}

[1]. Keeler JF, Simpson K H, Ellis FR and Kay SP. Effects of addition of hyaluronidase to bupivacaine during axillary brachial plexus block. British Journal of Anaesthesia 1992;68:68-71

[2]. Heath PJ, Brownlie GS and Herrick MJ. Latency of brachial plexus block. The effect on onset time of warming local anaestheticsolutions. Anaesthesia 1990;45:297-301

[3]. Okasha AS, El-Attar AM, Soliman HL. Enhanced brachial plexus blockade. Effect of pain and muscular exercise on the efficiency of brachial plexus blockade. Anaesthesia 1988;43:327-329

[4]. Bromage PR, Burfoot MF. Influence of physicochemical factors: hyaluronidase and potassium. British Journal of Anesthesia 1966;38:857-864

[5]. Winnie AP, tay CH, Patel KP, Ramamurthy S, Durrani Z. Pharmacokinetics of local anesthetics during plexus block. Anesthesia and Analgesia 1977;56:852-861

[6]. Lanz E, Theiss D, Jankovic D. Extent of blockade following various technique of brachial plexus block. Anesthesia and analgesia $1983 ; 62: 55-58$

[7]. Parris MR, Chamber WA. Effects of the addition of potassium to prilocaine or bupivacaine. British Journal of Anesthesia 1986;58:297-300

[8]. Hardy PAJ. Stellate ganglion block with bupivacaine and the effect of added potassium. Anesthesia 1989;44:398-399

[9]. Khosa DS, Thind SS, Gupta HK, Jain S. Effects of adding potassium chloride to lignocaine and bupivacaine solutions on the onset time and duration of brachial plexus block. Indian Journal of Anesthesia 1990;38:119-122

[10]. Hilgier M. Alkalinization of bupivacaine for brachial plexus block. Reganaesth 1985;10:59-61

[11]. Winnie AP. Plexus anesthesia: perivascular techniques of brachial plexus block. Philadelphia: WB Saunders, 1983:146-66 